\title{
Professor Nukem
}

\author{
Communicating Research in the Age of \\ the Experience Economy
}

\author{
Kuetil Sandvik \& Anne Mette Thorhauge
}

\begin{abstract}
The experience economy, that is, the creative and communicative turn in today's social, cultural and economic structures, implies, as explained by Pine and Gilmore (1999), that consumption is embedded in a communicative format that conveys some kind of experience to the consumer. The consumer in turn becomes more than just a passive user - he or she becomes an active participant in the experiential/communicative design. As such, the mode of consumption in the experience economy is an interactive and play-centric one. And the computer game embodies the very core logic of this experience economy. In the experience economy, the focus is not on consumption of commodities and services, but on the consumer's engagement in an experience that uses products, services and information as props and creative tools. Taking the user-centred mode of consumption as our point of departure, the present paper examines how the computer game format may be used as a new tool for communicating academic research to a broader audience. By applying some findings from a recent project, we will focus on the ways in which academic research can be communicated in a format that causes the recipient to take part in the process of communication and acquiring knowledge. This opens up new opportunities as well as challenges. On the one hand, communication of academic research is provided with new types of involvement, as the focus is not only on knowledge as content, but also on knowledge as activity. On the other hand, questions are raised here concerning what kind of knowledge is actually communicated/created in the process of active participation.
\end{abstract}

Keywords: computer games, experience economy, knowledge, research communication, playlike learning

\section{Introduction}

There is an increasing demand - put forward by politicians, business leaders, journalists - for researchers to communicate their research results not just within the academic system of conferences and peer-reviewed journals, but also in popularized formats to a broader audience. This raises the question of how scientific knowledge can be communicated in ways that can address and involve this broader audience.

The current article presents a research experiment into finding new formats for communicating the work of researchers. The project is grounded in the experience economy paradigm in which consumption of goods, services, information/knowledge has become a creative communication process in which the consumer is not only on the receiving 
end, but is also embedded in this process as a creative and participating agent. In this context, communicating research is not just a matter of transferring knowledge, but of creating communication designs that allow the recipient to get involved - in playful ways - in the knowledge-producing process itself. This is related to educational paradigms such as 'learning by doing' and 'play-like learning', and it is also related the use of (computer) games as educational tools, which will be discussed throughout the article in relation to our project. Furthermore, it is related to a systemic understanding of what knowledge is that does not limit knowledge to facts, but that also regards knowledge as understanding of what knowledge as such is and how knowledge-producing systems operate.

We wish to point out that, in the context of our project, the common denominator between the experience economy paradigm, these educational paradigms and a systemic approach to knowledge is that learning and acquiring knowledge are not just about reception, but also about production and participation. Communicating research to a broader audience in the age of the experience economy cannot - as we see it - just be a matter of transferring knowledge, but should facilitate ways in which the recipient can get involved in a participatory, knowledge-producing dialogue with the researcher(s) and the research material being communicated. He or she becomes a player participating in activities that should simulate research practice in various ways.

\section{Presentation of the Project}

Professor Nukem was an experiment on the use of computer games in communication of academic knowledge, and in this particular project academic research about the social and cultural impact of computer games. The project consists of two synergistically linked parts or two communication structures - a game-shaped part that should be played and a database-shaped part from which the user can get different kinds of information (about the project, research reports, etc.). The game-part of the project is designed in a relatively simple way by combining elements from two classical (computer) game genres: The quiz and the first-person shooter. In the game, the player is put in the role of a researcher - Professor Nukem - who in his studies on computer games is confronted with opponents in the form of prejudiced statements about computer games (like "computer games are addictive") and graphically displayed as monsters. To beat these opponents, the player has to choose a weapon in the form of a counter-argument. There are more counter-arguments to choose between, and the player has to select the right one, that is, the one based on scientific inquiries and reports. Accordingly, this initial sequence has a classical quiz structure, and it is followed by a sequence that has more in common with the first-person shooter. In this sequence, the player has to use his or her weapon to shoot the opponent. It has an evaluating function with regard to the quiz sequence, as the player's chances of overcoming the opponent depend on the choice of weapon. If the opponent loses life when hit, the right weapon has been chosen. If this is not the case, the wrong weapon has been chosen. If this happens, the player has the opportunity to put the game on hold and choose among the other alternatives. The shooting sequence ends as the player or the opponent runs out of life, and it is followed by an explanation that clarifies why a given counter-argument is right or wrong. These explanations represent the primary knowledge content that is to be communicated in the game, and they can also be found in the game's "walkthrough" in the database part of the project. The game has four different levels focusing on different aspects of computer 
games as they are often portrayed in the public: Computer games as addictive, computer games as violent, computer games as a socially isolating and, finally, computer games as a totally harmless activity.

Professor Nukem was part of a larger project focusing on the communication of research in the age of the experience economy. The project was called Exhibit Öresund ${ }^{1}$ and was coordinated by Diginet Öresund (http://www.diginet.org/), a network for the digital experience industries in the Öresund Region. Exhibit Öresund involved several universities in the Öresund region: Högskolan Kristianstad, University of Lund, University of Copenhagen and the Roskilde University-center. The resulting experiments involve the communication of academic research in the form of podcasts, simulations and - in the case of Professor Nukem - the computer game format.

\section{Computer Games and the Experience Economy}

Taking the experience economical, user-centred mode of consumption as our point of departure, Professor Nukem was an experiment on how the computer game format can be used as a new tool for communicating academic research in an engaging and participation-oriented way to a broader audience. Our main reason for choosing the computer game as a communication format was simply that computer games (and game-playing activities as such) embody the core logic of the experience economy: "staging experiences is not about entertaining customers, it's about engaging them" (Pine \& Gilmore 1999, p.30)

The experience economy may be defined as an economy that is based on the increasing demand in today's society for experience and that builds on the value of consumer creativity applied to both new and more traditional products and services:

When a person buys a service, he purchases a set of intangible activities carried out on his behalf. But when he buys an experience, he pays to spend time enjoying a series of memorable events that a company stages - as in a theatrical play - to engage him in a personal way (op. cit., p.2.).

Computer games may be said to be characterized by a basic principle in the experience economy, as stated by Arvidsson and Sandvik (2007): the implementation of the consumer (which in this context rather must be termed user or player) as a creative and productive agent in the economical circuit. Thus, computer games illustrate the core logic of the experience economy in which the focus is no longer on consumption of goods and services, but rather on engagement of the consumer in an experience in which goods and services are used as props and staging tools (Pine \& Gilmore, 1999) and which is characterized by mediatization of both production, marketing and consumption of experiences. Especially digital technologies - computers, mobile phones, Internet - constitute new experience economical arenas in which goods and services are embedded in digitally mediated and mediatized experiences that the consumer may be engaged and involved in, often via several media platforms.

As Pine and Gilmore point out in their book The Experience Economy (in which the concept is introduced for the first time), experiences as a mode of consumption are not so much about entertaining as about engaging the consumer, and this may take place on different levels of participation:

an experience may engage guests on any number of dimensions. [...] The first [...] corresponds to the level of guest participation. At one end of the spectrum lies 
passive participation, where customers do not directly affect or influence the performance. [...] At the other end of the spectrum lies active participation, in which customers personally affect the performance or event that yields the experience. $[\ldots]$ The second $[\ldots]$ dimension of experience describes the kind of connection, or environmental relationship that unites customers with the event or performance. At one end of this spectrum lies absorption - occupying a person's attention by bringing the experience into the mind - at the other end immersion - becoming physically (or virtually) a part of the experience itself. (op. cit., p.30-31)

But regardless the level of participation, designing experiences is a matter of scripting structures of actions and events that are open-ended in order to make room for consumer participation. Computer games are characterized by this logic: the consumer (the player) is participating in a way that contributes to the very experience the computer game has to offer. As such, computer games present themselves as performative in that they position the players as active subjects who have to take action in order produce and perceive the game experience. Looking at Professor Nukem from this perspective, the main purpose of the project is to create a communication design in which academic research is not only conceived by ways of reading a body of (more or less interactive) texts, but by ways of offering the user a certain role to play: In an entertaining and quite cartoonish way when playing the computer game part and in a more serious and investigative fashion when encountering the database part, the player is invited to play out a simulation of the activity of academic research and knowledge production, letting him/her experience the process of academic knowledge production, which includes making hypotheses, analysing and validating arguments, and so on.

The centrality of the computer game to the experience economy as a cultural paradigm is evidenced by the spectacular rise in the size of the computer games industry (by now outstripping that of the film industry), and by the prominent status of computer game aesthetics in films such as The Matrix, Lola Rennt, Timecode, eXistenZ, and Eternal Sunshine of the Spotless Mind. We see the computer game format reproduced in marketing (implementing casual games in a viral marketing campaign), advertising (using adver-games or in-game advertizing), in communicating culture (e.g., the game-like online versions of art museums such as the Louvre and the Van Gogh Museum) and so on. And it can also be seen in the computer game's importance to military applications such as flight simulators and other types of computer-based training systems, in the general "conflation and confusion of war and game" that has lead to "the development and proliferation of wargaming in the United States' defense and foreign policies" (Der Derian 2003, p. 38) as well as in the use of game-like vocabulary in the "war on terrorism' campaign. But this paradigmatic status is also, and perhaps primarily, illustrated by the technological form of the game medium itself.

As Arvidsson and Sandvik (2007) stated, computer games are part of the contemporary process of mediatization, by means of which new spatial and temporal dimensions of life are opened up for commoditization. This is particularly clear when the computer game spreads from the PC or the game console (PlayStation, Xbox and so on) to other technological platforms (the portable console, the cell phone or the PDA, or - even more significant - to the Internet), which make gaming possible in a much wider and more diverse range of situations, or when, as in the case of Electronic Arts' adventure game Majestic, the gameplay includes taking clues from mysterious midnight phone calls, anonymous e-mails and faxes, and fake websites. Majestic was promoted as a game that would "take over your life" and produces a game experience along the lines of what 
is experienced by Michael Douglas' character in David Fincher's The Game, and even though the game flopped and was taken of the market shortly after its release, Majestic forecasted the design trend called pervasive gaming, which creates gaming opportunities in the streets, offering a combination of tracking and location-based interaction, including cell phones with cameras, GPS and Internet access. A similar pervasive computer game (In Memoriam by Ubisoft) was released in 2004 with greater success; it includes e-mails and surfing the Internet as part of the gameplay. In these cases, the game platform tends to coincide with the contours of the life-world itself, as do other contemporary game formats such as live action role-play (see Sandvik \& Waade 2007).

As an interactive medium, the computer (in all its forms and shapes) facilitates communication processes that differ from traditional one-way formats, in that the user has to take action in order to keep the communication going. This is particularly the case when it comes to the interplay between the user and the fictional universe of the computer game. As Pearce (2002) points out, the computer as a dynamic two-way medium enables game designers to create a "new narrative ideology" in which the designer creates a narrative framework for the players' own game-stories. Here again, the characteristics of computer games coincide with the core logic of the experience economy: "Indeed, at its best, theming an experience means scripting a story that would seem incomplete without guests' participation" (Pine \& Gilmore, p.48). The designer does not simply function as a storyteller in the traditional sense. This becomes particularly clear with regard to so-called Massively Multiuser Online Role-playing Games (MMORPGs). These games, according to Pearce (2002), include both a meta-story in the shape of a pre-designed fiction world that contains a variety of story-lines structured in a progressive form like a series of missions for players to engage in, implying that players attain higher levels of experience, and a story-system that enables players to develop their own game stories in a variety of events and campaigns initiated by game clans within the framework of this world.

What we have here is a kind of user agency that is constituted by collective, collaborative and improvizational story production. It develops and evolves in realtime for the players who are logged on to the game. This 'realtime-ness' enables a blurring of the line between the fictitious world of the game and the world of the player, thus causing the game to transgress into the player's life-world where social activities and communities are mediatized by means of chat channels, blogs, and clan websites related to the game. Even though Professor Nukem is nowhere near entailing such a complex game model for its communication design, the large communicative and educational potential here can easily be imagined in light of what we have learned from this project. An example of how complex game models, such as those described above, can be put into educational use can be seen in the Danish project Homicide/Drabsag Melved, discussed in Jessen and Magnussen (2006). Here, the educational goal is to learn maths, physics and chemistry in the form of a role-playing game simulating a crime scene investigation, with the users in the role of technicians working with laboratory analysis of fingerprints, bloodstains, gunshot wounds and so on.

\section{Computer Games' Educational Potential}

Using the experience economy as a cultural paradigm and how computer games embody its core logic as our framework, we will put forward, in the following section, some thoughts on the educational potential of computer games, which is essential to how 
computer games may be used as a participation-oriented method of communicating knowledge. We will do so by focusing on computer games in a cultural and historical perspective, in light of modern theories of pedagogy, on computer games as part of children's culture, and finally, on computer games as role-play.

Our point of departure will be an obvious yet important one: Computer games are games and thus related to play and games in a broader sense. When analysing the educational potential of computer games, we can start by examining the role of games in our culture as such. As pointed out by Carsten Jessen (Jessen 2001, Jessen \& Magnussen 2006), in a broader cultural perspective games are not educational tools, instead they are means for creating playful social interactions. This does not mean that games do not involve learning. Many computer games are highly complex and require long learning processes, but (as also Piaget puts it when he analyses the role of children's play) "the learning is a means here, and the gameplay itself is the goal" (Jessen \& Magnussen 2006, p.23).

However, in a cultural and historical perspective, games have never played an unambiguous role as just fun and entertainment (see Huizinga, 1963). The value of games has also been religious, political and pedagogical. In ancient Greece, games had a religious value in confirming and describing the cosmology: the relationship between the gods and humans. Concerning the political value of games, games created the very space and format for the political debate that constituted democracy (and at the same time had a practical-political dimension in that different games of contest and combat where used in, e.g., the selection and training of the state's soldiers). And finally, in a pedagogical sense, games played an important role in the upbringing of children and fostering of the population. The point is that games have not just been part of the field of entertainment and leisure time activities, nor have they been limited to childhood activities.

Still, the invention of childhood in the 1700s has had an important impact on how we regard play and games (see Egenfeldt-Nielsen \& Smith, 2000). Play and games were increasingly regarded as something children do and something important in children's socialization: Play and games became a means for training children's ability to form social relations, and later on a cognitive-psychological perspective was added. Play and games train children's cognitive competences, as Jean Piaget points out (see Piaget, 1976). Piaget puts forth three categories of play - play of function, play of symbols and play of rules - which exercise these competences in different ways. One of the credos of cognitive psychology is that play is not just controlled by our instincts: it has to be learned and stimulated from the outside, as a stimulus for further learning. While the play of function is aimed at developing knowledge about the world and the play of rules is aimed at understanding as well as perceiving already fixed codes, the play of symbols (or role-play) is a kind of play that teaches the child to conceptualize the world and to abstract its thoughts.

Piaget's findings have had a great impact on modern theories of pedagogy and different learning theories proposing that we should regard learning as: a) complex processes, based on b) construction of knowledge, which are c) taking place across different contexts, d) placing the child in the centre, and whose e) primary modes are a combination of 'learning by doing' and 'learning by reflection' (see Sørensen, 2005). As a system of communication, this educational model, with its complex communicational processes, resembles the participatory and user-centred communicational logic of the experience economy and the interactive and play-centric communicational mode of computer games. This is opposed to a more traditional perspective on education, in 
which knowledge can be regarded as a package of facts and skills that is conveyed by the teacher and 'poured' into the pupils, who in turn acquire these facts and skills. Thus, in terms of communication, learning is a result of one-way transportation of information in a classical Jacobsonian fashion. It represents a communicative paradigm in which media are regarded as 'channels which transport information from one place to another' (Qvortrup 2007, p.19). Current learning theories (see Gee 2004, 2005) focus on knowledge more as an activity, as a process, rather than content, which may be transported from teacher to student:

Any actual domain of knowledge, academic or not, is first and foremost a set of activities (special ways of seeing, valuing, and being in the world). Physicists do physics. They talk physics. And when they are being physicists, they see and value the worlds in a different way than do non-physicists. The same goes for good anthropologists, linguists, urban planners, army officers, doctors, artists, literary critics, historians, and on and on. (Gee 2005, p.1)

If we were to erase the boundaries between these two different types of learning, the concept of education may be expanded and the learning situation will probably become more effective. Of course children still need to acquire certain skills: they need to learn how to read, write, do maths and so on, but their interest in computer games and in being active players may be put to work here, as seen in the Danish Magnus og Myggen 'learn-to-read' game (Ivanoff Interactive, 2006) and in the above-mentioned role-playing game Homicide/Melved (LearningLab Denmark, 2006), which has been designed for high school science classes. These, naturally, are games designed for educational purposes in the same way as Professor Nukem has been designed for the purpose of communicating academic research, but even non-educational games may be used as pedagogical tools. Just to give a couple of examples borrowed from Danish game researcher Simon Egenfeldt-Nielsen (see, e.g., Egenfeldt-Nielsen, 2005): If a class is to learn about the Medieval Ages, a realtime strategy game like Age of Kings may be used. In this game, you build your own kingdom using different units and buildings offered by the game. The player controls priests, knights, archers and so on. A variety of scenarios are based on historical events. The player may take on the responsibility for Joan of Arc's desperate attempt to save France or the Scottish riot against English superiority. Introducing this game as a tool in the teaching of history may give children a 'hands-on' insight into the mechanisms and logic of wars and power. If children are to learn about the laws of physics, a game like The Incredible Machine may be used as a pedagogical tool. In this game, a variety of objects should be arrange in such a way that a small ball will roll into a hole. The game design applies different physical principles in this setup, and thus the game may be used as a means for making science more appealing and less abstract to children.

These, of course, are just a couple of hypothetical examples of how computer games, which have not been designed for educational purposes, may be used as tools for specific pedagogical situations. But computer games are - as games in general - also potential tools for acquiring skills and knowledge on a more general level. The media play a crucial role in the way in which modern human beings acquire information and communicate with each other: Modern, digital communication is - due to its interactivity - based to a high degree on computer game formats. This is why playing computer games may be regarded as a means to train general media competences as well as other competences needed in today's hyper-complex society (cf. Qvortrup 2003). Here analysing and acting 
according to complex structures of meaning is vital and contains a learning potential that may transgress the game itself. As pointed out by Bo Kampmann Walther (2005), the ability to adapt, the ability to be part of mobile teams, to believe in oneself, the ability to communicate a strategy and to understand information - which characterize e.g. the players of online multiplayer games like Counter-Strike - are qualities demanded by, e.g., the business community. Thus, playing computer games may be regarded as a way of managing complexity in a society that could be called "polycentric, i.e. a society of many centers, many contexts and mandyu different basic assumptions and blind spots" (Qvortrup 2007, p.24)

Thus, computer games may function as media training and rehearsals in handling complexity, whether this takes place in the shape of violent play (when playing an action game like Grand Theft Auto), in the shape of mastering complex structures of meaning (when solving complicated puzzles in an adventure game like Myst or when building large systems in a strategy game like Civilization), or in the shape of experimentation with social structures (when playing the build-your-own-family game The Sims) (Sandvik 2006a).

In order to examine the educational potentials of computer games more closely, we may consider the communicative complexity of massive multi-player online role-playing games (in the tradition of Ultima Online and with World of Warcraft as today's most prominent example) and examine their resemblance to educational formats such as the role-play used as pedagogical tools in, e.g., educational drama (see Sandvik 2004, 2006b). The gameplay activities here resemble the learning ideals found in modern learning theory and the educational practice found in the use of role-play as a pedagogical tool: Here we find complex processes, facilitated by the game designers, focusing on construction of a world, its characters and stories and on building different social, political and economical systems. And these processes work across different contexts when players are operating both inside and outside the game's structure of actions and events, as agents in the game 'story' and at the same time as the creators of the very same story. And - as is true of all games - the player is placed in the centre as the main character in the course of events. And this double perspective, inherent in being both inside and outside the game's structure of actions and events, contains a great educational potential in which children can be both 'learning by doing' and 'learning by reflection', which is one of the important principles of modern educational theory. The concept here would be what Joseph Gee calls "game-like learning" (Gee 2005). Game-like learning is used to describe a learning situation in which technology-based games simulate complex worlds or systems, thus giving pupils the opportunity to learn about a scientific field through participation in activities that simulate a specific practice within a certain field of scholarship and research. As pointed out by Carsten Jessen, the computer game as media "with its construction of rules, interaction and narrativity" may be regarded as "an educational tool which [...] may support the development of educational competencies" (Jessen \& Magnussen 2006, p.7).

\section{Forms of Knowledge in Professor Nukem}

Thus, as has been argued above, computer games have a learning potential with regard to the communication of knowledge and training of specific competencies. As such, they also represent a new potential with regard to the communication of research and scientific knowledge. By turning the recipients into active participants, computer games 
are possible vehicles of pedagogical experiments focused on a more complex, active and engaging learning process, as pointed out in the previous section. Professor Nukem is such an experiment, where statements about computer games are partly organized into a relatively simple gameplay, partly into a more complex database structure. As described earlier, the player has to choose between various statements about computer games in order to win the game and is subsequently given an explanation based on scientific knowledge. While the integration of these statements into a gameplay potentially heightens the player's feeling of engagement, it also raises some critical issues with regard to the concept of knowledge. That is, while computer games most certainly require knowledge and competences in order to be played and thus imply a learning process, the specific knowledge and competences involved are not necessarily equivalent to the knowledge to be communicated. Thus, it is necessary to be aware of what knowledge is actually to be communicated and whether this knowledge is actually an integrated part of playing the game.

On one level (the other levels will be dealt with below), Professor Nukem builds on a conception of knowledge as content and relates as such to what Gee calls "content fetish" (Gee 2004):

The content fetish is the view that any academic area, whether physics, sociology, or history, is composed of a set of facts or a body of information and that the way learning should work is through teaching and testing such facts and information. (Gee 2005, p.1)

Knowledge is regarded in this context as a phenomenon that can be organized into categories of right and wrong. There are right answers and wrong answers, and the right answers are those that can be supported by research reports and scientific publications. The player wins the game by choosing those counterarguments that are defined in this way as the right ones, and he/she subsequently receives an explanation as to why a given answer is right or wrong. These explanations represent the primary knowledge content that is to be communicated in the game, which means that the communicative value of the game depends on the player's willingness to read them. From a design point-of-view, we have facilitated this activity by removing any kind of time pressure on the quiz sequences. The player can take his/her time to choose a weapon or read an explanation without losing any points on that account. Still, this does not guarantee that the player will read the explanations - this ultimately depends on the player and the player group. What counts as relevant knowledge in order to play the game depends on the characteristics and motivations of the players.

When we developed the game, we defined our target group as schoolteachers, parents and politicians with an interest in children's use of computer games and media in general. We expected this group to possess sufficient reading skills to read the explanations and we expected them to have a level of motivation for playing that went beyond simply mastery of the game and towards gaining knowledge about research on the social and cultural impact of computer games. We have some indications that this is also the case. Thus, as part of the game development process, we asked a group of respondents to play the initial version of the game and comment upon it. The respondents who agreed to help us were a couple of grandparents aged 50+, a housewife and mother of three, a school teacher and a journalist. Apart from commenting on specific functionalities in the game, most of the respondents commented on the specific wording of the questions, answers and explanations in the game. For instance, they commented on the difficulty 
level and on the grammatical structure of specific explanations. This implies that they actually read the text elements in the game as part of their playing activity.

However, after the game was published online and introduced to a broader group of players, we had a wider range of responses. These responses can be exemplified by a couple of teenagers we got a chance to observe playing the game on an informal occasion. The teenagers were a girl aged 13 and a boy aged 18 who teamed up and played the game together, with the explicit goal of getting on top of the high score list shown at the end of the game. After a few minutes of gameplay, the following analysis was given: Quite easy: the right answers are the long ones we don't understand. The teenagers did not care about the content of the questions and answers - their main motivation was to master the game, that is, as quickly and effectively as possible to kill the monsters and to proceed through the level structure, and to this end, the written content seemed to have little value to them. Baker et al. (2004) called this type of player behaviour "off-task behaviour":

This set of strategies, which we will refer to as "gaming the system", consists of behaviour aimed at obtaining correct answers and advancing within the tutoring curriculum by taking advantage of regularities in the software's responses - systematically misusing the software's feedback or help instead of actively thinking about the material. (ibid.)

This does not mean that their gaming activity did not involve any knowledge at all, but theirs was another type of knowledge: Recognition of the basic game logic (gameplay and the game mechanic characteristics of the quiz and first-person shooter), of a general pattern in the wording of the statements, and of how this was to be operationalized into successful manipulation of the game.

What the teenagers playing Professor Nukem did was apply their skills as computer game players, their knowledge about game genres, gameplay and game mechanics. When we are exploring how computer games may be used as educational tools and tools for communication knowledge, it is important to take this type of media-specific knowledge - which is acquired by players through playing games - into consideration.

It is evident that successful gaming (that is the playing of computer games) requires a particular kind of player socialization in which the player acquires the knowledge necessary to play the game. To pinpoint the main characteristics of computer games in this context, computer games may be described as computer-mediated settings in which the player is invited to take part as a major agent in the interactive structures of actions and events: They present themselves as interactive and "play-centric" (Pearce, 2002). Computer games are interactive in that they are constituted by interactions between a structure of actions and events (however complex and multi-threaded) and a player's agency within and in relation to this world and structure. They are play-centric in that this interaction between game and player is not limited to mere reading or watching, but must be played. Thus, interactive and play-centric structures of actions and events imply a specific structure of communication and, as a result of this, a transformation of the recipient.

Many researchers along the line of Brenda Laurel (1991) have regarded the interactive communication structures of the computer and thus also computer games as a type of participatory theatre. And the same use of theatre metaphors may be found in Pine and Gilmore's description of the communicational logics of the experience economy (Pine and Gilmore 1999). From merely playing the role of spectator to the dramatic story unfolding in front of him/her, the player is offered a role within the action and 
event structure itself. But the transformation is even more radical than that: If we stick to theatre-metaphorical terms as they have been employed, the interactive and playcentric structure found in computer games dissolves the line between spectator and the structure of actions and events taking place on the stage; it dissolves the notion of spectator and stage all together, which is why it is not entirely correct to assume that interactive systems ("the computer as theatre") mimic a situation in which the audience members enter the stage and become actors (Laurel, 1991, p.16). It makes little sense to talk about actors and audience in the traditional sense. There is no point outside the game from which an audience is intended to watch and therefore there is no one for the player as actor to act for. A game is not meant to be watched like a theatre performance. The central issue in a game is play. This means there are different demands on interactive and play-centric fiction than on traditional fictions, which are meant to be read or watched. Narrative contingency, psychological character development, depth of characters as well as story play a minor role compared to possibilities for the recipient to play a role within the story. The point is not to discover, reveal or to read the plot (see Brooks, 1984), but to play the plot.

In order to function as a competent player, one has to have acquired both the knowledge and skills that are generally available within the language of computer games in general: One must be able to function as a 'social individual' within the world of computer games. This connects to the dyadic system of various game universes and interactive structures embedded in computer games that the player can influence. This structure of game universe and possible player actions is what we usually term a game's gameplay. Gameplay may be described as the pace and eye-and-hand coordination skills as well as the cognitive effort that the game requires of the player (Crawford, 1997, p.21). Different gameplay genres have demanded different sets of player qualifications throughout the history of computer games, and thus have created traditions for the socialization of 'competent players'. Action games require the ability to operate the game interface at a high speed and to react in real-time to the multitude of choices constantly presented by the game, while adventure games demand skills of pattern recognition, logical reasoning, puzzle solving and so on; strategy games build on a player's ability to construct and handle increasingly complex systems (a family, a city, an ecosystem, etc.). Even though the game genre landscape is much more complex now than when Chris Crawford formulated his trend-setting genres in The Art of Computer Game Design (1982), and contemporary game design tends to blend genres into action-adventure, action-role-playing, and realtime strategy, classic notions of gameplay genres still play an important role when games are released and promoted. As such, a new game will always be released into a context constituted by gaming communities (groupings of different types of players who exchange experience and engage in different kinds of fan-activities connected to certain games or certain types of game), as well as by the game tradition established by the historical development of different game genres.

At the level of the particular game, players are socialized through a wide variety of strategies: voluminous manuals, extensive introduction sequences, informative cutscenes, tutorial levels, and so on. In highly competitive games such as action games, the possibilities for the player to get better at playing the game (pursuing 'high-score') are ensured by designers introducing 'save-game' functionalities that allow the player to install points in the dramatic story that he/she can return to in case the development proves to be unfortunate (e.g., the player-character dies). In games that focus on some kind of collective story-producing process, the gameplay includes the possibility for the 
player to acquire important tools (acting techniques, dramaturgical competences and so on) that are needed to create fiction. This is the case with MMORPGs. These games contain not only tools for creating and developing a character, but also different kinds of 'practice grounds' in which players can try out their characters and certain possibilities for creating dramatic action. They are thus socialized into the game by the process of getting acquainted with the game rules, game interface and game fiction, and they use this knowledge to play the actual game, but also when encountering new games.

Returning to Professor Nukem, it is evident that this game involves several types of knowledge depending on the players. Whereas the knowledge to be communicated consists of explicit statements about computer games, the teenagers who tested the game ignored this construction and applied another kind of knowledge - a more or less tacit recognition of the language patterns in the quiz sequence combined with gameplay skills and knowledge about game genres (here: the first-person shooter genre). We describe this recognition as "more or less tacit", as it is only made explicit because we asked the players about it. Although players may choose to verbalize and make explicit this type of knowledge in order to share, it does not have to be made explicit in order to be useful. In this way, the two types of knowledge involved differ with regard to their explicitness. Furthermore, whereas the explicit statements refer to the subject matter of the game, the analysis given by the teenagers refers to the way the game is constructed. The two types of knowledge involved are associated with different aspects of the game system.

Accordingly, if computer games are to be used as tools for communicating about research, we have to be aware of which kind of knowledge the term "research" is expected to cover and how this type of knowledge works in computer games. In the following section, we will suggest the distinction between factual, situational and systemic knowledge as a useful classification in this regard.

\section{Factual, Situational and Systemic Form: A Theory of Knowledge}

If games are to be used as tools for communicating about research, we need to define which form of knowledge we consider research to be and how it relates to other forms of knowledge. That is, we need a general explanation of the concept of knowledge. One such explanation is given by Lars Qvortrup, who takes a systemic approach to the question. Thus, with reference to Polanyi's concept of tacit knowledge (Polanyi, 1967), he makes a basic distinction between immediate and reflexive capacities (Qvortrup 2004, p. 71-73). Immediate capacities are usually referred to as skills, whereas reflexive capacities are usually referred to as knowledge. However, Qvortrup points out that both are forms of knowledge. In the case of Professor Nukem, the explicit statements as well as the tacit understanding count as knowledge even though they represent different types of knowledge.

Qvortrup furthermore addresses two basic philosophical traditions with regard to the definition of knowledge: Cartesianism based on the works of Descartes in the $17^{\text {th }}$ century, and phenomenology based on the works of Husserl and Heidegger at the beginning of the $20^{\text {th }}$ century. From a classical Cartesian point of view, knowledge is a token of the relationship between the subject and the world (Qvortrup 2004, p. 76). Thus, as Cartesianism separates the subject and the world into two fundamentally different categories, res cogitans and res extensa, knowledge resides in the subject's contemplation of the world. However, this separation of subject and world into two distinct categories has been met with a great deal of critique, and phenomenology represents an alternative perspective. 
According to a phenomenological standpoint, the subject and the world cannot be separated. The subject is in the world and a part of the world, and this is a basic condition for all knowledge (see Heidegger, 1935). According to this perspective, knowledge is not a token of the relationship between the subject and the world, it is a token of the subject's being in the world - a way of handling the complexity of the world (Qvortrup 2004, p. 82 ). The subject not only contemplates the world - it also contemplates its own being in the world as well as the world as a condition for the contemplation of the world. This gives way to several orders of knowledge: Factual knowledge, situational knowledge, systemic knowledge and world knowledge, as summarized below:

Table 1. An Overview of Knowledge Forms

\begin{tabular}{|l|l|l|}
\hline Knowledge form & Knowledge system & Knowledge term \\
\hline Factual knowledge & Knowledge about the world & Qualifications \\
\hline Situational knowledge & Knowledge about knowledge & Competences \\
\hline Systemic knowledge & Knowledge about the knowledge system & Creativity \\
\hline World knowledge & Collective basis of knowledge & Culture \\
\hline
\end{tabular}

Source: Qvortrup 2004, p. 86.

World knowledge is a relatively abstract construction that resides not in the individual subject, but in the social community in general. As regards the other knowledge forms, however, they represent some very useful tools indeed. Seen in relation to Professor Nukem, factual knowledge represents a statement about the world such as: "gamers seldom display all necessary symptoms of addiction". In comparison, situational knowledge refers to the specific knowledge situation: The statement above is part of a game, and it may thus represent a right or a wrong answer, which means that choosing it has consequences for the further progression of the game. Finally, systemic knowledge refers to the knowledge system that underlies at given statement. In this case, systemic knowledge represents the various research traditions that have different definitions of the concept of addiction, which determines whether it makes sense to apply a given definition in specific situations.

What we wished to communicate with the project was not just research results, but also the work processes of the academic researcher. By applying an experience- and participation-based communication design and a learning-by-doing mode, the intention behind Professor Nukem as not just to communicate knowledge on the first level in Qvortup's model, but also on the $2^{\text {nd }}$ and $3^{\text {rd }}$ level, dealing with how knowledge is created and how knowledge systems function.

Thus, according to the table above, what do we communicate when we communicate research? Are we communicating factual knowledge in the form of statements about the world or are we communicating systemic knowledge in the form of knowledge about those systems that condition the statements? We believe we do both. That is, communicating research means making obvious the connection between statements about the world and those knowledge systems that provide the statements with their truth-value. In the case of Professor Nukem, what is to be communicated is the relation between the counterarguments and the research that renders them true or false. As the teenagers' strategy indicates, this only happens to some degree. Thus, some of Professor Nukem's shortcomings can give us an idea about future improvements. 


\section{Future improvements: The Lesson Learned from Professor Nukem}

As described above, Professor Nukem is an experiment and part of a larger project focusing on the communication of research in the age of the experience economy. As such, it has been conducted under certain time and money constraints that limited the sort of game concept we could develop. For instance, development of a complex strategy game or a detailed simulation game was far beyond the resources at hand, and the result is a rather simple flash-based webgame that illustrates certain communication principles. As such, the game has its obvious shortcomings, and these shortcomings may bring about even more interesting conclusions than its possible advantages.

We have presented and demonstrated the project in various educational settings, and here a number of critical points have been raised that may serve to advance our discussion about games as conveyers of scientific knowledge a little further. Most severely, the game has been called a "brochure in the disguise of a game" where the game is at best "a bad excuse for bringing forth a specific story". What this critique points to is the lack of coherence between content and form - knowledge and gameplay - in Professor Nukem. This is a problem because "gameplay is what the player will mainly focus upon in order to win the game".

Of course, players are not all alike. As described earlier on, teenagers and schoolteachers played the game differently, and thus gameplay is a variable concept too. Whereas the game may have been designed to be played in a specific way, different player groups may choose to play it in alternative and surprising ways. However, the critique is quite appropriate, as there is indeed no connection between the knowledge to be learned in the game and the different ways of manipulating the game in practice. For instance, there is no obvious reason why a correct answer should turn into a useful weapon, whereas a wrong answer renders the weapon useless. This may make sense at a metaphorical level, but it is easily ignored in the act of playing the game.

Restating this critique in terms of the knowledge categories presented above, Professor Nukem does not integrate the factual, situational and systemic knowledge forms involved in the game sufficiently. As already mentioned, the teenagers ignored the written content of the game and relied instead on an identification of the general language pattern and how it was to be operationalized into successful manipulation of the game. According to the table above, they focused mainly on the situational level, ignoring the content of the statements and their relation to a general knowledge system. And the reason why they could do so was that the situational knowledge - the knowledge required to play the game - was not sufficiently integrated into the other knowledge forms of the game. It was possible to play the game without taking into consideration the content of the statements. Thus, an important aim of further experiments should be to develop game concepts in which the immediate or reflexive capacities required to master the game, that is, the situational knowledge, is more closely connected to those reflexive capacities that are expected to be communicated by the game, that is, the factual and systemic knowledge. In an ideal situation, the knowledge required to master a game should be the logical link between the factual and the systemic knowledge of the game.

An additional point has to be made here. The knowledge required to master a game is rarely stated explicitly. For instance, the teenagers' recognition of the game's knowledge patterns had a more or less tacit character, in that they only verbalized it because we asked them to do so. In Qvortrup's terms, their knowledge about the game had the form of an immediate capacity with a strong potential to become a reflected capacity. However, the aim of a project like Professor Nukem is to communicate knowledge in 
the form of reflected capacities. Other types of educational games like, for instance, flight simulators may have immediate capacities, such as an intuitive understanding of a complex relationship or change in behavioural patterns, as their principal aim. In comparison, the communication of research as defined above implies making obvious the connection between specific statements and general systems of knowledge, that is, causing the player to reflect on this connection. In other words: It is not enough that the player manages to do the right thing or make the right choice in the game. The player must also be aware of this choice and able to explain why it is better than the alternatives. Ideally, the very structure of the gameplay should support and ensure this transformation of immediate capacities into reflected capacities. This does not mean that such games should not imply immediate capacities. This is not possible. Rather, the relevant immediate capacities should be transformed into reflected capacities by way of the gameplay itself.

This is quite ambitious. Integrating the factual, situational and systemic knowledge involved in playing a game and doing this by transforming immediate capacities into reflected capacities will require much more advanced game concepts than that of Professor Nukem. Most likely this will also imply larger budgets and more technical expertise involved in the development of the game. And these resources are not always at hand. However, economical constraints should not become an easy excuse for lack of original thinking. Professor Nukem certainly could have taken other forms that may have fulfilled our aim more successfully. For instance, an obvious solution that was not chosen would have been to use communication between players as a resource and a way to bring about an integration between knowledge and gameplay in the game. Thus, Professor Nukem should rather be seen as a first, modest step in the direction of communicating academic research by way of the computer game format, and hopefully more attempts at this will appear in the future.

Even though the project has its flaws and shortcomings, it demonstrates important issues that need to be discussed and tested in further research into communicating research in popularized formats outside the academic sphere. As such, our project has been an attempt to raise questions about what knowledge is and about how communication of knowledge in the age of the experience economy is not just a matter of transferring information, but about facilitating communication processes that focus on learning and acquiring knowledge as creative and participatory processes. Especially (computer) games facilitate those types of processes that transform recipients into participants (player), which is why they have great educational and communicative potential in this context.

\section{Note}

1. The project is now completed, and the website containing Professor Nukem no longer exists. The gamepart of the project may still be played at http://www.uovo.dk/clients/diginet/.

\section{Literature}

Arvidsson, A. \& Sandvik, K. (2007) 'Gameplay as Design: Uses of Computer Players' Immaterial Labour', in Stald, G. \& Fetveit, A. (eds.) Northern Lights. London: Intellect.

Baker, R.S. et. al. (2004) 'Off-task Behavior in the Cognitive Tutor Classroom: When Students Game the System', Conference paper. Vienna: CHI 04.

Brooks, P. (1984) Reading for the Plot. Cambridge MA: Harvard University Press. 
Crawford, C. (1997) The Art of Computer Game Design, http://www.mindsim.com/mindsim/corporate/artcgd. pdf, accessed September 5. 2006. (Origi-nally published in 1982).

Der Derian, J. (2003) 'War as Games', in The Brown Journal of World Affairs.

Egenfeldt-Nielsen, S. (2005) Beyond Edutainment. Copenhagen: IT University (Dr. diss.).

Egenfeldt-Nielsen, S. \& Smith, J.H. (2000) Den digitale leg [Digital play]. Copenhagen: Hans Reitzels Forlag.

Gee, J.P. (2004) Situated Language and Learning: A Critique of Traditional Schooling. London: Routledge.

Gee, J.P. (2005) 'Game-Like Learning : An Example of Situated Learning and Implications for Opportunity to Learn', http://www.academiccolab.org/resources/documents/Game-Like\%20Learning.rev.pdf, May $7^{\text {th }}$ 2008.

Heidegger, M. (1935) Sein und Zeit. H. 1. Halle: Niemeyer.

Huizinga, J. (1963) Homo ludens. Copenhagen: Gyldendal.

Jessen, C. (2001) Børn, leg og computerspil [Children, play and computer games]. Odense: University of Odense Press.

Jessen, C. \& Magnussen, R. (2006) "Naturfaglig praksis og spil-lignende læring” [Science pratice and gamelike learning], in MONA. Matematik- og Naturfagsdidaktik-tidsskrift for undervisere, forskere og formidlere 2006-2.

Kampmann, Walther, B. (2005) Konvergens og nye medier [Convergence and new media]. Copenhagen: Gyldendal

Laurel, B. (1991) Computer as Theatre. New York: Addison.Wesley Publishing Company.

Pearce, C. (2002) 'Towards a Game Theory of Game', http://www.cpandfriends.com/writing/first-person.html, September 5. 2006.

Piaget, J. (1976) Play - Its Role in Development and Evolution. New York: Penguin Books.

Pine II, J. \& Gilmore, J.H. (1999) The Experience Economy: Work Is Theatre \& Every Business a Stage. Boston, MA: Harvard Business School Press.

Polanyi, M. (1967) The Tacit Dimension. Garden City, N.Y.: Doubleday.

Qvortrup, L. (2003) The Hypercomplex Society. New York: Peter Lang.

Qvortrup, L. (2004) Det vidende samfund: mysteriet om viden, laering og dannelse [The knowing society: the mystery of knowledge, learning and education]. Copenhagen: Unge Pædagoger.

Qvortrup, L. (2007) 'Medium, Mediation, Remediation, Immediatication', in Philipsen, H. \& Qvortrup, L. (eds.) Moving Media Studies - Remediation Revisited. Copenhagen: Forlaget Samfundslitteratur.

Sandvik, K. (2004) "Fortælling som kollektiv proces - om kollektivt tilrettelagte fiktionsverdener i teatret og på internettet og deres fascinationskraft og dramapædagogiske potentiale" [Storytelling as collective process - on collective design of fictional worlds in theatre and on the Internet and their powers of fascination and educational potential], in Krøgholt, I. (ed.). DRAMA - Nordisk Dramapcedagogisk Tidsskrift, temanummer, 'Kollektive Skabelsesprocesser', nr. 3, 2004.

Sandvik, K. (2006a.) 'Evaluation of Quality in Computer Games', in Carlsson, Ulla: Nordicom Review 2(2006) Special Issue. Göteborg: Nordicom.

Sandvik, K. (2006b.) 'In and Out of Character. Complex Role-play in an Online World', Arbejdspapirer no. 11. University of Aarhus: Center for Digital Æstetik-forskning.

Sandvik, K. \& Waade, A.M. (2007) 'I Play Roles, Therefore I Am: Placing Larp in a Broader Cultural Perspective', in Donnis, J., Gade, M. \& Thorup, L. (eds.) Lifelike. Copenhagen: Projektgruppen KP07/Landsforeningen for Levende Rollespil.

Sørensen, E. (2005) "Lær af computerspil!" [Learn from computer games], in Kampmann Walther, B. \& Jessen, C. (eds.) Spillets verden. En bog om computerspil. Copenhagen: University of Education Press. 